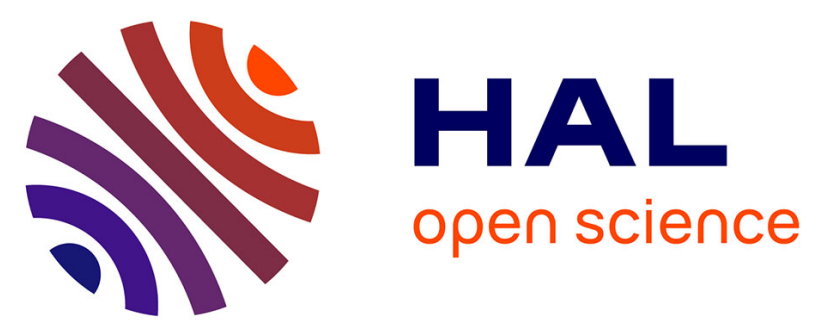

\title{
1. Spatial and temporal evolution of the optical thickness of the Pinatubo aerosol cloud in the northern hemisphere from a network of ship-borne and stationary lidars
}

S. I. Avdyushin, G. F. Tulinov, M. S. Ivanov, B. N. Kuzmenko, I. R. Mezhuev, Bruno Nardi, Alain Hauchecorne, Marie-Lise Chanin

\section{To cite this version:}

S. I. Avdyushin, G. F. Tulinov, M. S. Ivanov, B. N. Kuzmenko, I. R. Mezhuev, et al.. 1. Spatial and temporal evolution of the optical thickness of the Pinatubo aerosol cloud in the northern hemisphere from a network of ship-borne and stationary lidars. Geophysical Research Letters, 1993, 20 (18), pp.1963-1966. 10.1029/93GL00485 . insu-03131969

\section{HAL Id: insu-03131969 \\ https://hal-insu.archives-ouvertes.fr/insu-03131969}

Submitted on 4 Feb 2021

HAL is a multi-disciplinary open access archive for the deposit and dissemination of scientific research documents, whether they are published or not. The documents may come from teaching and research institutions in France or abroad, or from public or private research centers.
L'archive ouverte pluridisciplinaire HAL, est destinée au dépôt et à la diffusion de documents scientifiques de niveau recherche, publiés ou non, émanant des établissements d'enseignement et de recherche français ou étrangers, des laboratoires publics ou privés. 


\title{
1. SPATIAL AND TEMPORAL EVOLUTION OF THE OPTICAL THICKNESS OF THE PINATUBO AEROSOL CLOUD IN THE NORTHERN HEMISPHERE FROM A NETWORK OF SHIP-BORNE AND STATIONARY LIDARS
}

\author{
S.I. Avdyushin, G.F. Tulinov, M.S. Ivanov, B.N. Kuzmenko, I.R. Mezhuev \\ Federov Institute of Applied Geophysics, Moscow, Russia \\ B. Nardi ${ }^{1}$, A. Hauchecorne, M.-L. Chanin \\ Centre National de la Recherche Scientifique/Service D'Aeronomie, France
}

\begin{abstract}
The vertical profiles of the extinction coefficient and the total optical thickness of the Pinatubo aerosol layer obtained from a network of 5 Rayleigh-Mie lidars are presented here. Three ship-borne lidars (PROFESSOR ZUBOV', PROFESSOR VIZE', HENRI POINCARE*) and two fixed lidar stations (OHP* and CEL*) are operated respectively by the Roscomhydromet ${ }^{\dagger}$, of Russia and of the Service d'Aeronomie du CNRS* of France. The measurements presented are in the altitude range $15-35 \mathrm{~km}$. They were obtained between July 1991 - April 1992 and cover $8^{\circ} \mathrm{S}-60^{\circ} \mathrm{N}$ latitude and $80^{\circ} \mathrm{W}-6^{\circ} \mathrm{E}$ longitude. This represents extensive coverage of the western sector of the northern hemisphere, which is partly coincident with UARS satellite coverage. Optical depths of up to 0.2 were observed and maximum extinction coefficient values of $0.03 \mathrm{~km}^{-1}$ were obtained at $24 \mathrm{~km}$ and $18^{\circ} \mathrm{N}$ latitude.
\end{abstract}

\section{Introduction}

Since the eruptions of Mount Pinatubo between 12-16 June 1991 , it has been an important concern to characterize the aerosol cloud that resulted from this eruption, since the presence of aerosols has a large effect on remote sounding measurements and on the chemistry and radiative budget of the lower stratosphere. We present here the optical thickness and extinction measurements, taken over a ten month period in equatorial and northern midlatitudes with a network of Russian and French lidars. These data give a good indication of the vertical, horizontal and temporal morphology of the Pinatubo cloud and could be used to validate or correct UARS data.

\section{Instrumentation}

The lidar network consists of five Rayleigh-Mie lidars operating in the wavelength range, $532-589 \mathrm{~nm}$. Two Russian lidars stations operated by the Roscomhydromet are on-board the ships PROFESSOR ZUBOV and PROFESSOR VIZE. Three French lidar stations operated by CNRS are located at the Observatory of Haute-Provence (OHP: $44^{\circ} \mathrm{N}, 6^{\circ} \mathrm{E}$ ), at the Centre d'Essai des Landes at Biscarosse (CEL: $44^{\circ} \mathrm{N}, 1^{\circ} \mathrm{W}$ ) and on-board the military ship HENRI POINCARÉ based at Brest (herein referred to as LIMA).

The three French lidar stations have been described in previous publications [Chanin and Hauchecorne, 1991; Hauchecorne et al., 1991, 1992], so their description here will be limited to the tabulated summary in Table 1 . However, it should be pointed out here that a significant difference exists in the receiver configurations of the OHP and CEL lidar stations. OHP uses two independent receiving telescopes for the two channels corresponding to the low and high altitude ranges of

\footnotetext{
${ }^{1}$ Visiting research fellow from The University of Michigan Space Physics Research Laboratory, Ann Arbor.
}

Copyright 1993 by the American Geophysical Union. the measurements, whereas CEL uses one telescope in conjunction with a beam splitter which is sensitive to polarization angle of the Rayleigh backscattered component of photons. The OHP lidar configuration is therefore more ideally suited for the measurements presented in this paper.

The Roscomhydromet ship-borne lidar station on-board PROFESSOR ZUBOV operates on a $539.5 \mathrm{~nm}$ wavelength, using a doubled yttrium aluminum laser, which emits 0.2 $\mathrm{J} /$ pulse at $25 \mathrm{~Hz}$. The pulse counting system has a $1 \mu \mathrm{s}$ resolution corresponding to an altitude resolution of 150 meters. The transmitting telescope produces a beam of width $5 \times 10^{-4} \mathrm{rad}$. The diameter of the parabolic mirror of the receiving telescope is $110 \mathrm{~cm}$, with a focal length of $300 \mathrm{~cm}$. To minimize the background photons, an interference filter is placed in front of the detector with a bandpass width of $0.5 \mathrm{~nm}$ FWHH (full width at half height).

The Roscomhydromet ship-borne lidar station on-board PROFESSOR VIZE uses a dye laser with an R6W active element and operates at $589 \mathrm{~nm}$. It emits $0.4 \mathrm{~J} / \mathrm{pulse}$ at $5 \mathrm{~Hz}$. The pulse counting system has an effective $2 \mu$ s resolution ( 300 meter altitude resolution). The transmitting and receiving telescopes have the same characteristics as those of the ZUBOV lidar, and the interference filter has a bandpass width of 0.8 nm FWHH. These characteristics are summarized in Table 1.

\section{Measurements}

\section{Analysis}

The extinction coefficient $\alpha$, is calculated with expression:

$$
\alpha(z)=\beta_{\text {aer }}(z)\left(\frac{\beta_{\text {aer }}}{\alpha}\right)^{-1}
$$

where the aerosol backscatter to extinction ratio in the brackets is a measurable quantity. The value used throughout the calculations was a constant value of $0.04 \mathrm{sr}^{-1}$, which corresponds to the $532 \mathrm{~nm}$ wavelength at $20 \mathrm{~km}$ after a major volcanic eruption. In fact the aerosol backscatter to extinction ratio can vary with aerosol content [Jäger and Hofmann, 1991] and is also expected to be variable with altitude, especially after a large volcanic eruption [Deshler et al., 1992; Thomason and Osborn, 1992]. The value chosen is roughly twice as large as expected under normal, aerosol-free conditions. The ratio was assumed to be constant in time because the posteruption conditions were essentially present for the bulk of this data-set, certainly for the interesting part of it. It was assumed

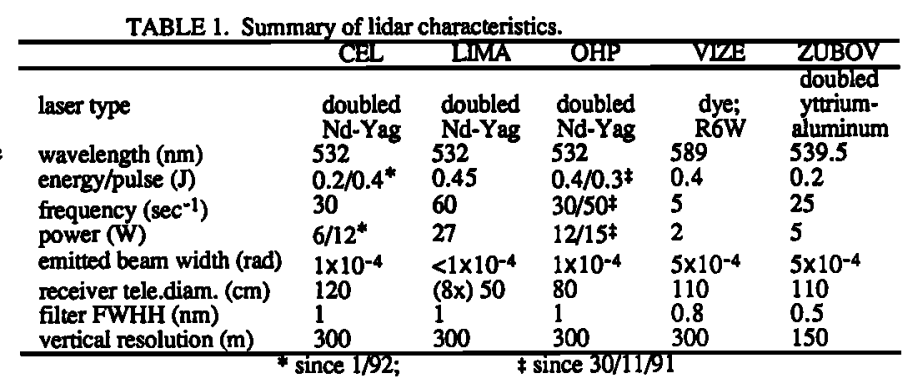




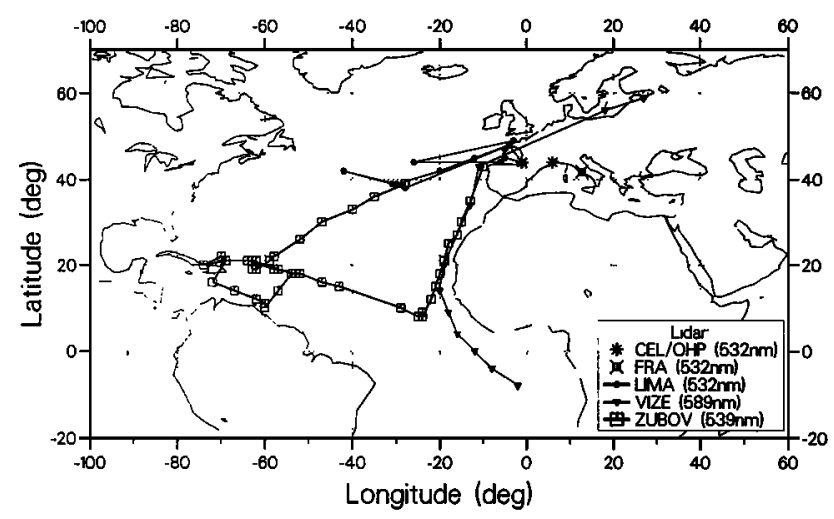

Fig. 1. Path of the 3 ships, PROFESSOR ZUBOV, PROFESSOR VIZE and HENRI POINCARE (LIMA) are shown on a Mercator projection along with the locations of the fixed stations, CEL, OHP and FRA.

constant with altitude because applicable measurements of this constant are highly limited. $\beta_{\text {aer }}$ is the scattering coefficient of the Mie scattering from aerosols, obtained from,

$$
\beta_{\text {aer }}(z)=(\operatorname{SR}(z)-1) \cdot \beta_{\text {Ray }}(z)
$$

where $\operatorname{SR}(z)$ is the scattering ratio obtained from the lidar measurements [Nardi et al., this issue] and $\beta_{R_{2 y}}$ is the Rayleigh backscattering coefficient at $532 \mathrm{~nm}, 5.7 \times 10^{-32} \mathrm{~m}^{2} \mathrm{sr}^{-1}$. The wavelength dependence of the Rayleigh scattering cross section is accounted for in the VIZE data $(589 \mathrm{~nm})$ with a correction factor of $\left(589^{-4} / 532^{-4}=0.666\right)$. The optical thickness given at $15 \mathrm{~km}$ altitude is calculated as,

$$
\tau_{15 \mathrm{~km}}=\int_{z=15}^{\infty} \alpha(\mathrm{z}) \mathrm{dz}
$$

\section{Data-set}

The paths of the three ships, ZUBOV, VIZE and LIMA, during the period of measurements are summarized in Figure 1. The locations of the fixed stations, CEL and OHP are shown as asterisks.

The ZUBOV lidar made measurements during 48 nights within the 73 day period between 11-July-1991 and 21September-1991. During the measurement sequence, the ship

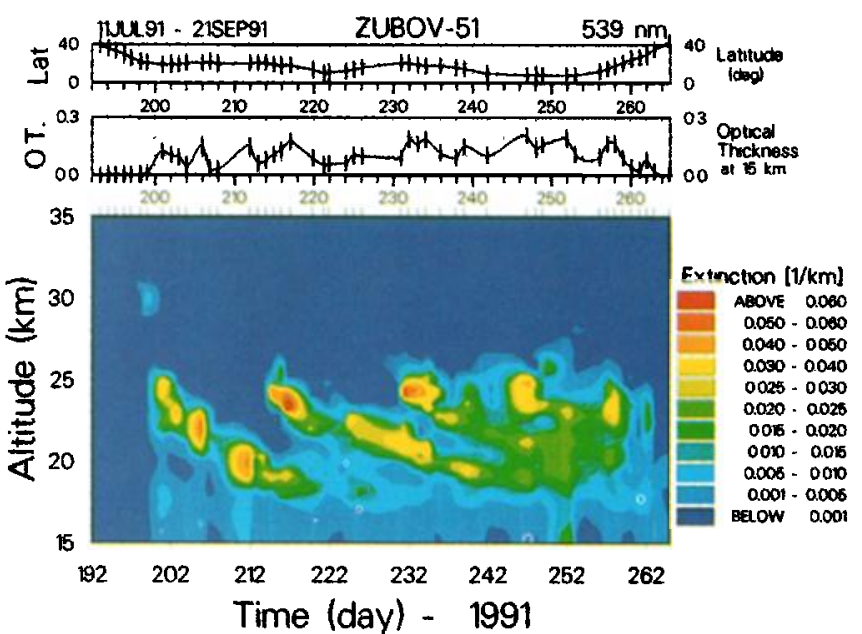

Fig. 2. The ZUBOV extinction coefficient, measured at $539 \mathrm{~nm}$ is shown as a function of time and altitude. Markers are placed on the abscissa above and below the map to indicate where data is available. The line plots above show the total optical depth at $15 \mathrm{~km}$ and the latitude position of the ship, respectively.

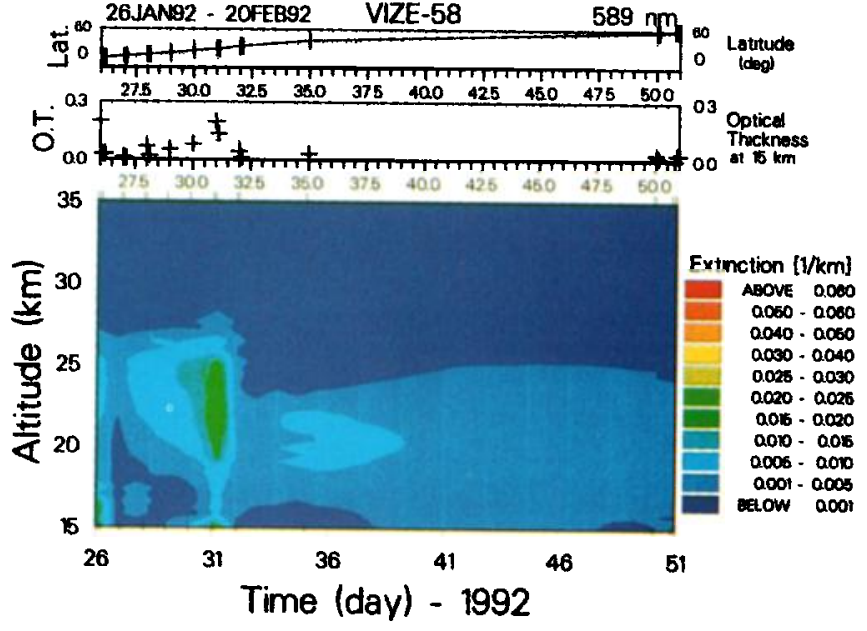

Fig. 3. The VIzE extinction coefficient, measured at $589 \mathrm{~nm}$ is shown as a function of latitude and altitude with the same format as in Figure 2.

followed a triangular route from $40^{\circ}$ latitude in the Atlantic Ocean, toward Cuban waters and down to $10^{\circ}$ latitude, toward the west coast of Africa and finally northward toward the northwestern coast of Spain. A large fraction of the data are confined to the $8^{\circ} \mathrm{N}-22^{\circ} \mathrm{N}$ latitude range. The extinction coefficient and optical thickness obtained on this path are plotted in Figure 2 along with the latitude position of the ship.

The VIZE lidar made measurements during 20 nights within the 26 day period between 26-January-1992 and 20-February1992. During the measurement sequence, the ship followed a northward route from the south-Atlantic, toward the northwestern coast of Spain and back to St. Petersburg. Data were obtained between latitudes $8^{\circ} \mathrm{S}-34^{\circ} \mathrm{N}$ and $56^{\circ} \mathrm{N}-60^{\circ} \mathrm{N}$, separated by a 15 day gap. The extinction coefficient and optical thickness are plotted in Figure 3.

The LIMA lidar made measurements during 26 nights within the 198 day period between 3-June-1991 and 17 December-1991. During the measurement sequence, the ship made a round trip from the northwest of France to the midAtlantic, in the latitude region $38^{\circ} \mathrm{N}-49^{\circ} \mathrm{N}$. The extinction coefficient and optical thickness are plotted in Figure 4.

The two stationary ground-based lidar stations have been running in an operational mode: OHP since 1978 and CEL since 1986. We have isolated the data since July 1991, two

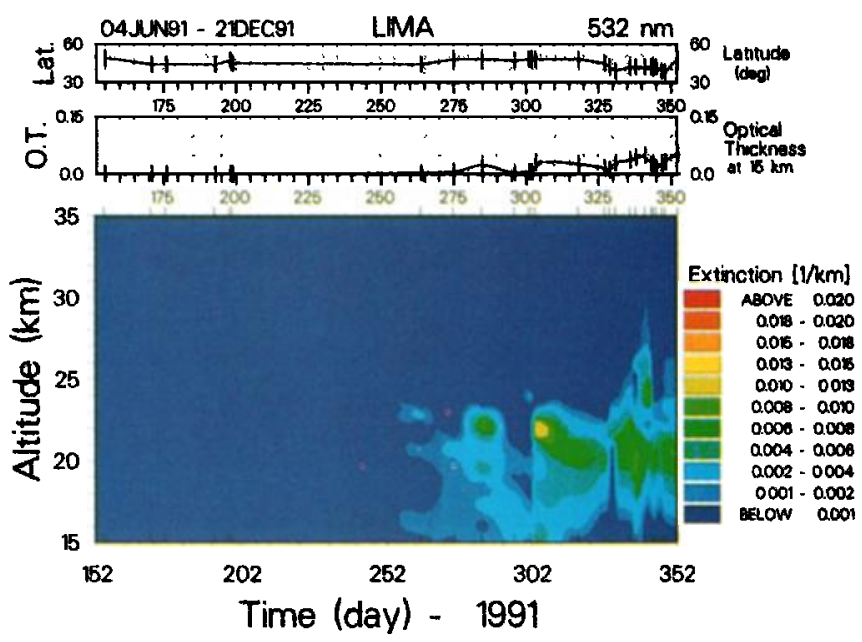

Fig. 4. The LIMA extinction coefficient, measured at $532 \mathrm{~nm}$ is shown as a function of time and altitude with the same format as in Figure 2. 

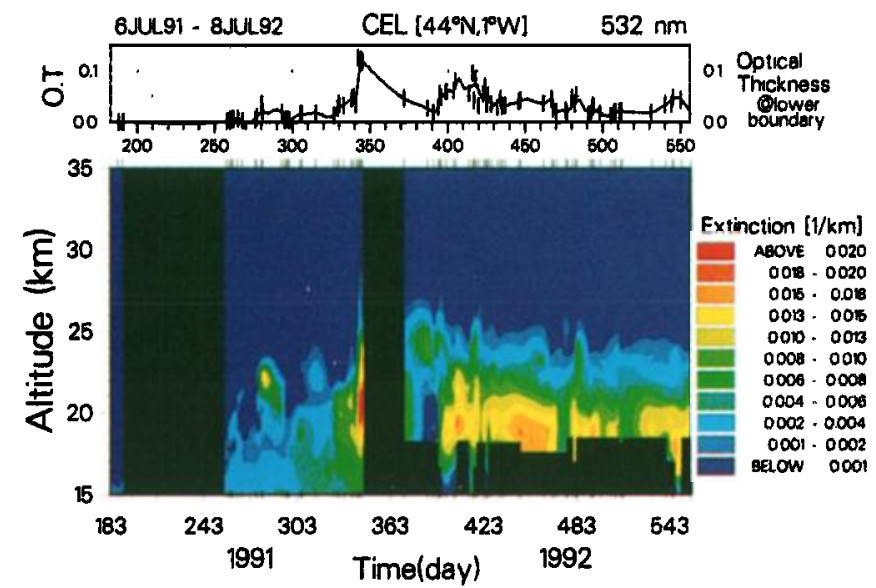

Fig. 5. The CEL extinction coefficient, measured at $532 \mathrm{~nm}$ is shown as a function of time and altitude. Black masks suppress regions where no data are available over extended periods or altitude ranges. Note that the optical depth plot above indicates the optical depth at the lowest available altitude, not necessarily $15 \mathrm{~km}$.

weeks after the Pinatubo eruptions of 12-16 June, which also correspond to the times where ship-borne data are available. Extensive data available for June show no signs of aerosols and are not reported here. The lidar station at CEL obtained measurements during 81 nights within the 369 day period between 6-July-1991 and 8-July-1992. The extinction coefficient and optical thickness are plotted in Figure 5. The lidar station at OHP obtained measurements during 149 nights within the 416 day period between 1-July-1991 and 19 August-1992. The extinction coefficient and optical thickness are plotted in Figure 6.

In all of these figures the altitude dependent extinction coefficient is shown as a function of time, with the total optical thickness (down to $15 \mathrm{~km}$ ) plotted overhead. The abscissa is given in the day of the year; in the jump from 1991 to 1992 the day numbers continue to increase from 366 upwards. It is important to note that markers are placed on the abscissa above and below the map to indicate nights where data are available. Black masks are placed over the larger areas where no data are available to avoid misinterpretation of structure artificially introduced by the interpolation. Note that the color scale used with the CEL, OHP and LIMA plots is different from that used with the Russian data because much lower extinction values were obtained at midlatitudes.

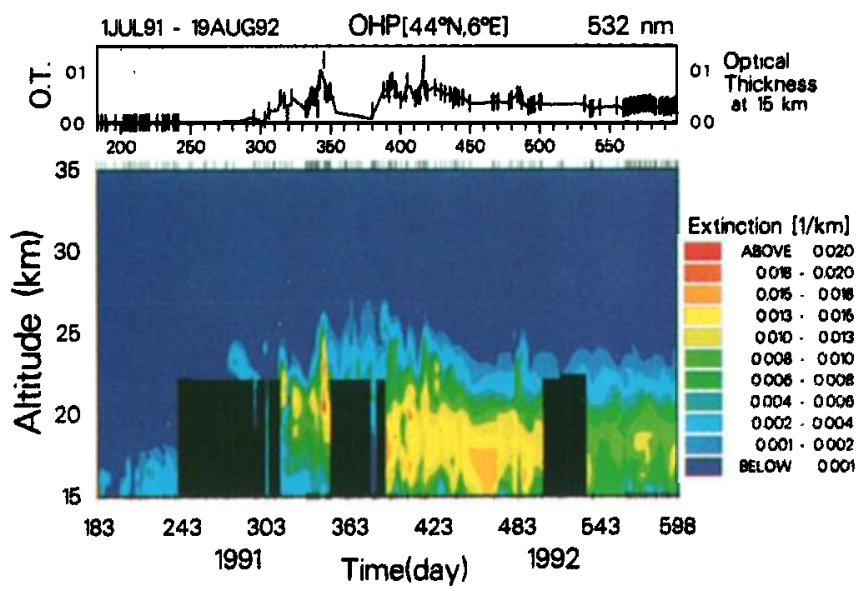

Fig. 6. The OHP extinction coefficient, measured at $532 \mathrm{~nm}$ is shown as a function of time and altitude with the same format as in Figure 5.

\section{Comparison}

Individual profiles are compared where a reasonable degree of coincidence occurs, that is where existing measurements are within less than $1000 \mathrm{~km}$ and 24 hours of each other. In this data-set, coincidence occurred only for the stationary sites, CEL and OHP, as well as with a lidar facility stationed at Frascati, Italy (FRA: $41.8^{\circ} \mathrm{N}, 12.7^{\circ} \mathrm{E}$ ) [Gobbi et al., 1992]. The ship-borne measurements given here covered specific regions in the Atlantic Ocean and therefore coincided neither with the stationary sites nor with each other.

Figure 7 shows a comparison of several individual extinction coefficient profiles between the various stationary sites. Extinction coefficients for Frascati were calculated using the scattering ratio profiles given in Gobbi et al. [1992] and were compared with OHP measurements (Figure 7a). The vertical structure and the magnitude of the extinction coefficient are very similar, with a slight difference in peak altitude of the layer. In the 3 part sequence of Figure 7(b-d), extinction coefficients from the OHP and CEL lidar stations are compared for 3 nights within an 8 day period. On any given night a difference in the fine vertical structure of the extinction coefficient is observed between stations, however the total optical thicknesses above $15.1 \mathrm{~km}$ are comparable. The first plot (b) shows an aerosol feature centered at $20 \mathrm{~km}$, while the last plot (d) shows a significantly stronger double peaked feature with extinction coefficients reaching $0.02 \mathrm{~km}^{-1}$ at 21 and $23 \mathrm{kms}$. Both plots show a high level of similarity
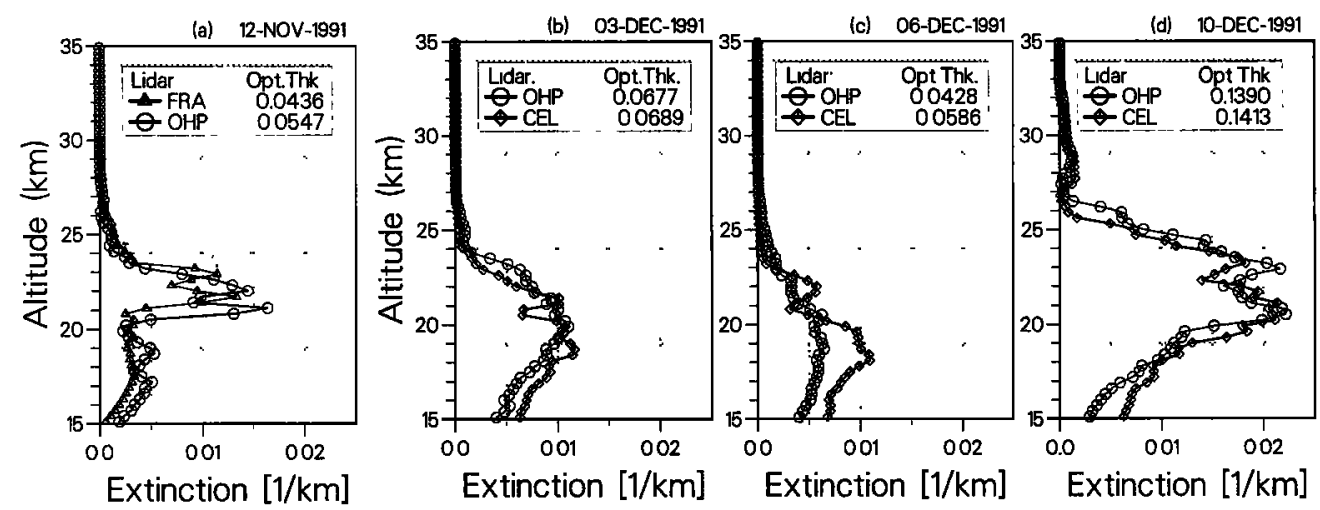

Fig. 7. The extinction coefficient profile at $532 \mathrm{~nm}$ are compared (a) between the lidars of Frascati $\left(41.8^{\circ} \mathrm{N}, 12.7^{\circ} \mathrm{E}\right)$ and OHP $\left(44^{\circ} \mathrm{N}, 6^{\circ} \mathrm{E}\right)$. Similar comparisons are shown for 3 profiles within an 8 day period (b), (c), (d) between the lidar

stations at $\mathrm{OHP}$ and CEL $\left(44^{\circ} \mathrm{N}, 1^{\circ} \mathrm{W}\right)$. The distance between lidar stations in all cases shown is approximately $600 \mathrm{~km}$. The total optical thicknesses above $15.1 \mathrm{~km}$ are indicated in the legend boxes. 
between the aerosols over two stations ( $<2 \%$ difference in optical depth). However in the plot (c), both the vertical structure and the optical depth show a greater disparity $(25 \%$ difference in optical depth). It is probable that the boundary of a strong aerosol cloud is passing overhead in (c), causing the difference over the 2 stations in this transition stage.

It is also of benefit to compare optical depths obtained by ZUBOV at the lower latitudes with independent measurements made with different techniques. Optical depths were obtained by Valero et al. [1992] using airborne radiometer measurements of the solar radiative flux within the wavelength range 380-1064 nm. His values of optical depth at $500 \mathrm{~nm}$ of $0.15-0.3$ in the latitude range $20^{\circ} \mathrm{N}-10^{\circ} \mathrm{N}$ respectively, are slightly higher than the ZUBOV optical depths at $532 \mathrm{~nm}$ of $0.05-0.2$ in the same latitude range. However this difference can be attributed, at least in part, to the wavelength difference of the measurements; the optical depth is expected to decrease at higher wavelengths in this spectral region.

\section{Discussion}

The data show that there is a great deal of variability in the structure of the aerosol cloud. However, it can be generally stated that the extinction coefficients indicate presence of aerosols primarily in the altitude range of $17-25 \mathrm{~km}$, though they have on occasion been measured as high as $32 \mathrm{~km}$.

Comparison of the generally low latitude measurements of ZUBOV and VIZE with those at the midlatitude region of OHP, CEL, LIMA shows that at low latitudes there is a presence of a strong high altitude cloud at $24 \mathrm{~km}$ as well as a weaker low altitude cloud at $17 \mathrm{~km}$, whereas at midlatitudes there is the persistent presence of only the lower altitude cloud near and below $20 \mathrm{~km}$ with weaker, higher altitude features that pass through sporadically.

At low latitudes (equatorward of $40^{\circ} \mathrm{N}$, primarily between $8^{\circ} \mathrm{N}-22^{\circ} \mathrm{N}$ ) the mean optical depth was 0.1 and reached values of almost 0.2 on a regular, nearly periodic basis. The maximum extinction coefficient was $0.08 \mathrm{~km}^{-1}$ at $23-24 \mathrm{~km}$ measured by ZUBOV in July 1991 (day 217).

At midlatitudes $\left(40^{\circ} \mathrm{N}-44^{\circ} \mathrm{N}\right)$, the first evidence of aerosols appeared in early July at altitudes of $15-17 \mathrm{~km}$, in agreement with Gobbi et al. [1992], with measured extinction coefficients of $0.013 \mathrm{~km}^{-1}$ at OHP (day 183) and $0.0024 \mathrm{~km}^{-1}$ at CEL (day 188). The first clear evidence of elevated aerosol concentrations above $18 \mathrm{~km}$ appeared at CEL and LIMA on 21-September-1991 (day 264), with extinction values of $0.0025 \mathrm{~km}^{-1}$. High extinction levels at this altitude were first detected at all three midlatitude sites during the second week of October (days 280-286), when extinction coefficients of up to $0.017 \mathrm{~km}^{-1}$ were measured at CEL. On average, the optical depth at midlatitudes was near 0.05 . However on one occasion (December 8-11; days 342-5), both CEL and OHP measured high optical depth values of up to 0.125 with peak extinction coefficients of $0.021 \mathrm{~km}^{-1}$ at $23 \mathrm{~km}$ (CEL). On this same occasion, higher than normal extinction values (up to $0.001 \mathrm{~km}^{-1}$ ) were measured at record high altitudes (near 30 $\mathrm{km})$ by all three midlatitude sites.

The data at CEL in the 6 month period after January 1992 have been normalized to the mean OHP measurements of the same period because low extinction values at the CEL station resulted from a polarization effect introduced into the detected signal by the beam splitter. Though there is some evidence of periodic behavior in OHP, CEL and LIMA data, it is by far much less pronounced than for the lower latitude data of ZUBOV, which is further studied in the follow-up article [Nardi et al., this issue]. This means that aerosol features detected are probably aerosols that have broken off from the main low latitude cloud and that pass through the field-of-view of the midlatitude lidars one time on their way to higher latitudes.

Care should be used in interpreting the data because it is not always available at evenly spaced intervals. One can see that in the measurements of CEL, OHP and LIMA, significantly long data gaps may exist. One consequence of this is that certain aerosol features may be missing in the data presentation.

The data presented here shows clearly, the advantage of having a network of ground-based and ship-borne lidar facilities to obtain the medium and long term behavior of the aerosol cloud on a global basis.

Acknowledgements. The contribution to this work by B. Nardi was supported by the NSF Program for Long and Medium Term Research at Foreign Centers of Excellence; grant number INT/9101978 to the University of Michigan. The authors wish to thank the anonymous reviewers as well as A. Sarkissian for their helpful comments.

\section{References}

Avdyushin, S.I., G.F. Tulinov, M.S. Ivanov, B.N. Kuzmenko, I.R. Mezhuev, Y.P. Dudoladov, Lidar observations of Pinatubo eruption products in the Atlantic stratosphere from PROFESSOR ZUBOV and PROFESSOR VIZE research ships. Report of the Academy of Science of Russia [in press, 1992].

Chanin, M.-L., A. Hauchecorne, Lidar study of the structure and dynamics of the middle atmosphere, Indian J. Radio Sp. Sci, 20, 1-11, 1991.

Deshler, T., D.J. Hofmann, B.J. Johnson, W.R. Rozier, Balloonborne measurements of the Pinatubo aerosol size distribution and volatility at Laramie, Wyoming during the summer of 1991, Geophys. Res. Lett., 19, 199-202, 1992.

Gobbi, G.P., F. Congeduti, A. Adriani, Early stratospheric effects of the Pinatubo eruptions, Geophys. Res. Lett., 19 , 997-1000, 1992.

Hauchecorne, A., M.-L. Chanin, P. Keckhut, Climatology and trends of the middle atmospheric temperature (33-87 $\mathrm{km}$ ) as seen by Rayleigh lidar over the south of France, $\mathrm{J}$. Geophys Res., 96, 15297-15309, 1991.

Hauchecorne, A., M.-L. Chanin, P. Keckhut, D. Nedeljkovic, LIDAR monitoring of the temperature in the middle and lower atmosphere, Appl. Phys. B. Photophysics and Laser Chemistry, B55, 29-34, 1992.

Jäger, H., D. Hofmann, Midlatitude lidar backscatter to mass area, and extinction conversion model based on in situ aerosol measurements from 1980 to 1987, Appl. Opt., 30, 127-138, 1991.

Nardi, B., M.-L. Chanin, A. Hauchecorne, S.I. Avdyushin, G.F. Tulinov, M.S. Ivanov, B.N. Kuzmenko, I.R. Mezhuev, 2. Morphology and dynamics of the pinatubo aerosol layer in the northern hemisphere as detected from a ship-borne lidar, Geophys. Res. Lett., [this issue].

Thomason, L.W., M.T. Osborn, Lidar conversion parameters derived from SAGE II extinction measurements, Geophys. Res. Lett., 19, 1655-1658, 1992.

Valero, F.P.J., P. Pilewskie, Latitudinal survey of spectral optical depths of the Pinatubo volcanic cloud_derived particle sizes, columnar mass loadings, and effects on planetary albedo, Geophys. Res. Lett., 19, 163-166, 1992.

Weinmann, J.A., Derivation of atmospheric extinction profiles and wind speed over the ocean from satellite-borne lidar, Appl. Opt., 27, 3994-4001, 1988.

S. I. Avdyushin, M. S. Ivanov, B. N. Kuzmenko, I. R. Mezhuev, G. F. Tulinov, Federov Institute of Applied Geophysics, Rostokinskaya st. 9, 129226 Moscow, Russia.

M.-L. Chanin, A. Hauchecorne, B. Nardi, Service D'Aéronomie, Centre National de la Recherche Scientifique, B.P. №. 3, 91371 Verrières le Buisson CEDEX, France.

(Received: 24 August 1992; revised: 16 December 1992; accepted: 20 January 1993) 